\title{
Effects of the CRH Receptor Antagonist CP-154,526 on Intravenous Cocaine Self-administration in Rats
}

\author{
Nick E. Goeders, Ph.D., and Glenn F. Guerin, B.S.
}

The role for corticotropin-releasing hormone $(\mathrm{CRH})$ receptors in the maintenance of intravenous cocaine self-administration in rats was investigated using the centrally active, small molecule CRH1 receptor antagonist CP-154,526. In these experiments, adult male Wistar rats were allowed alternating 15-min periods of access to food reinforcement and cocaine selfadministration $(0.125,0.25$ or $0.5 \mathrm{mg} / \mathrm{kg} /$ infusion) during daily 2-h sessions. A 1-min timeout separated access to the two reinforcers. Pretreatment with CP-154,526 produced doserelated decreases in cocaine self-administration without affecting food-reinforced responding, suggesting a specific effect of the antagonist on cocaine-maintained behavior. Drug intake was decreased across several doses of cocaine, with the dose-response curve for cocaine self-administration shifted downward and flattened, suggesting that CP-154,526 decreased cocaine reinforcement. Furthermore, responding on the cocaine lever following CP-154,526 pretreatment was significantly suppressed, even during the first 15 min of the session, a time when rats typically sample the cocaine lever during extinction, suggesting that $C R H$ receptors may also be involved in some of the conditioned effects of cocaine as well. These data are discussed in terms of the role for $\mathrm{CRH}$ in the neurobehavioral effects of cocaine.

[Neuropsychopharmacology 23;577-586, 2000] (C) 2000 American College of Neuropsychopharmacology. Published by Elsevier Science Inc.
KEY WORDS: Cocaine; Corticotropin-releasing hormone; Reinforcement; Self-administration; Rat

During the past several years, research from our laboratory has focused on the potential involvement of the hypothalamic-pituitary-adrenal (HPA) axis in cocaine reinforcement. The HPA axis consists of a complex, well-regulated interaction between the brain, the anterior pituitary gland, and the adrenal cortex. The initial step in the activation of the HPA axis is the neuronally

From the Departments of Pharmacology \& Therapeutics (NEG, GFG) and Psychiatry (NEG), Louisiana State University Health Sciences Center, Shreveport, LA.

Address correspondence to: Nick E. Goeders, Ph.D., Department of Pharmacology \& Therapeutics, Louisiana State University Health Sciences Center, 1501 Kings Highway, P.O. Box 33932, Shreveport, LA 71130-3932. Tel.: 318-675-7863; Fax: 318-675-7857; E-mail: ngoede@lsuhsc.edu

Received March 14, 2000; revised May 3, 2000; accepted May 5, 2000. regulated secretion of the peptide corticotropin-releasing hormone (CRH) from the parvocellular division of the paraventricular nucleus (PVN) of the hypothalamus. $\mathrm{CRH}$ is released by the hypothalamus into the adenohypophyseal portal circulation to act on the pituitary to induce the secretion of adrenocorticotropin hormone (ACTH). ACTH diffuses through the general circulation until it reaches the adrenal glands. There it stimulates the biosynthesis of adrenocorticosteroids, most notably the glucocorticoids, cortisol (in humans) and corticosterone (in rats), which results in their secretion from the adrenal cortex.

Cocaine has been reported to stimulate HPA axis activity in a manner analogous to various stressors, which indicates that this system has the potential to influence many of the neurochemical and behavioral effects of the drug. For example, the acute administration of cocaine dose-dependently increases plasma concentrations of corticosterone, $\mathrm{ACTH}$, and $\beta$-endorphin in rats 
(Moldow and Fischman 1987; Rivier and Vale 1987; Borowsky and Kuhn 1991). Cocaine also stimulates the release of ACTH and cortisol in humans (Mendelson et al. 1989; Baumann et al. 1995) and non-human primates (Sarnyai et al. 1996) by increasing the peak amplitude of secretory pulses of these hormones without altering pulse frequency, suggesting that these increases are driven by hypothalamic CRH (Mendelson et al. 1989; Teoh et al. 1994; Sarnyai et al. 1996). Cocaine-induced increases in ACTH and corticosterone in rats can be blocked by pretreatment with the $\mathrm{CRH}$ antagonist $\alpha$-helical $\mathrm{CRF}_{9-41}$ (Sarnyai et al. 1992a), by immunoneutralization of CRH with an anti-CRH antibody (Rivier and Vale 1987; Sarnyai et al. 1992a), or by bilateral electrolytic lesions of the PVN (Rivier and Lee 1994), indicating that these increases are also mediated by the cocaine-induced release of CRH from parvocellular neurons in the PVN. Accordingly, it has been reported that cocaine administration also results in increases in hypothalamic CRH mRNA (Zhou et al. 1996; Rivier and Lee 1994) and alters $\mathrm{CRH}$ receptor binding measured autoradiographically in various regions of the rat brain (Goeders et al. 1990). These data suggest that the complex relationship between cocaine reinforcement and corticosterone secretion we have previously reported (Goeders and Guerin 1996; Goeders 1997) may ultimately result from actions on hypothalamic CRH. The following experiments were therefore designed to determine the effects of pretreatment with CP-154,526, a centrally active, small molecule CRH1 receptor subtype antagonist (Mansbach et al. 1997), on intravenous cocaine self-administration in rats. This compound was selected for study in these experiments because, unlike peptide antagonists such as D-Phe $\mathrm{CRF}_{12-41}, \mathrm{CP}-154,526$ enters the brain following systemic administration (Schulz et al. 1996; McCarthy et al. 1999), which makes it a potentially more useful tool for investigating the effects of $\mathrm{CRH}$ in cocaine reinforcement. In fact, this compound has recently been reported to attenuate the electric footshock-induced reinstatement of cocaine- and heroinseeking behavior (Shaham et al. 1998), suggesting the involvement of $\mathrm{CRH}$ in the relapse to drug seeking. We report here that $\mathrm{CRH}$ is involved in the maintenance of ongoing cocaine self-administration as well.

\section{METHODS AND MATERIALS}

Adult male Wistar rats $(n=58$; Harlan Sprague Dawley) 80-100 days old at the start of the experiments were used. The rats were housed singly in cages equipped with a laminar flow unit and air filter in a temperatureand humidity-controlled, AAALAC-accredited animal care facility on a reversed 12-h light/dark cycle (lights on at $1800 \mathrm{~h}$ ) with free access to water. Rats were also allowed free access to food until their free-feeding body weights increased to approximately $380-400 \mathrm{~g}$. These rats were subsequently maintained at $85-90 \%$ of their free-feeding body weights by presentations of food pellets (P.J. Noyes, $45 \mathrm{mg}$ ) during the behavioral sessions and/or by supplemental post-session feeding (Purina Rat Chow) throughout the course of the experiments. All procedures were carried out in accordance with the $\mathrm{NIH}$ "Principles of Laboratory Animal Care" (NIH publication No. 85-23).

Each rat was implanted with a chronic indwelling jugular catheter under pentobarbital anesthesia (50 $\mathrm{mg} / \mathrm{kg}$, i.p.) with methylatropine nitrate pretreatment $(10 \mathrm{mg} / \mathrm{kg}$, i.p.) using previously reported procedures (Koob and Goeders 1989; Goeders et al. 1998). The catheter ( 0.012 in i.d. $\times 0.025$ in o.d., silicone tubing) was inserted into the right posterior facial vein and pushed down into the jugular vein until it terminated outside the right atrium. The catheter was anchored to tissue in the area and continued subcutaneously to the back where it exited just posterior to the scapulae through a Marlex mesh ${ }^{\circledR} /$ dental acrylic/22-gauge guide cannula (Plastic Products) assembly that was implanted under the skin for attachment of a leash. The stainless steel spring leash (Plastic Products) was attached to the guide cannula assembly and to a leak-proof fluid swivel suspended above the cage. Tubing connected the swivel to a 20-ml syringe in a motor-driven pump (Razel) located outside the chamber. The swivel and leash assembly was counter-balanced to permit relatively unrestrained movement of the animal. The animals were injected with sterile penicillin $G$ procaine suspension (75,000 units, i.m.) immediately before surgery, and they were allowed a minimum of 4 days to recover following surgery. The swivel and leash assembly was always connected during the experimental sessions. At the end of each session, the leash was disconnected and a dummy cannula was inserted into the guide before the rats were returned to their home cages. The patency of the catheters was tested immediately after the end of the session each Wednesday. If blood could be obtained via the catheter, then it was judged to be patent. If not, then the rat was injected via the catheter with methohexital sodium (1.5 mg, i.v.). An immediate light anesthesia indicated that the catheter was functional.

Standard plastic and stainless steel sound-attenuating operant conditioning chambers (Med-Associates, Inc.) were used to run the behavioral experiments. Each experimental chamber was equipped with two response levers (Med-Associates, Inc.) mounted on either side of a food pellet dispenser located on one wall of the chamber, and a stimulus light was located above each lever. The chambers were also equipped with an exhaust fan that supplied ventilation and white noise to mask extraneous sounds. An IBM-compatible personal computer and interface system (Med-Associates, Inc.) 
was used to program the procedures and collect the experimental data.

Rats were trained to respond under a multiple, alternating schedule of food reinforcement and cocaine selfadministration as described previously (Goeders et al. 1998). During the food component of the schedule, a stimulus light located directly above the food response lever was illuminated to indicate the availability of food reinforcement. Initially, each depression of the food response lever resulted in a brief darkening of the food stimulus light $(0.6 \mathrm{~s})$ and the delivery of a food pellet (45 mg). A 25-s timeout followed the delivery of each food pellet. During this timeout, the stimulus light was darkened and responses on the food lever were counted but had no scheduled consequences. Responding on the other (i.e., cocaine) lever during the food component also had no scheduled consequences. The response requirement for the food lever was gradually increased over several sessions from continuous reinforcement to a fixed-ratio 10 (FR10) schedule whereby 10 responses were required for food presentation. Following $15 \mathrm{~min}$ of access to food, all stimulus lights in the chamber were darkened for a 1-min timeout. Following the timeout, the stimulus light above the cocaine response lever was illuminated to indicate the availability of cocaine. Initially, each depression of the cocaine response lever resulted in a brief darkening of the stimulus light and an infusion of cocaine $(0.125,0.25$ or $0.5 \mathrm{mg} / \mathrm{kg} /$ infusion in $200 \mu \mathrm{l} 0.9 \% \mathrm{NaCl}$ delivered over $5.6 \mathrm{~s}$ ). A 20 -s timeout period followed each infusion. The response requirement for cocaine was gradually increased to a FR4 schedule of reinforcement. After $15 \mathrm{~min}$ of access to cocaine and another 1-min timeout, the rats were again allowed $15 \mathrm{~min}$ of access to the food component of the schedule. Access to food and cocaine alternated in this manner every $15 \mathrm{~min}$ during the 2-h behavioral sessions so that each rat was exposed to food and cocaine for four 15-min periods each. Each behavioral session began with $15 \mathrm{~min}$ of access to either food or cocaine, and this alternated daily. Sessions were conducted at the same time each day, Monday through Friday. Stable baselines of responding occurred when the total number of cocaine and food presentations, as well as the number of presentations during each of the four exposures each session, varied less than $10 \%$ for three consecutive sessions.

Prior to testing with $\mathrm{CP}-154,526$, the rats were repeatedly exposed to cocaine extinction (Goeders et al. 1998). On extinction test days, a saline vehicle syringe was substituted for the cocaine syringe normally present, and responses on the "cocaine" lever only resulted in infusions of saline. The rats were presented with these "extinction probes" on drug test days (i.e., Tuesdays and Fridays) until stable, reproducible, "extinction-like" behavior was observed. Extinction-like behavior was deemed to occur when the rates and pat- terns of responding did not vary more than $10 \%$ during at least two consecutive extinction probes. Cocaine extinction probes continued to be run approximately every 2 weeks until the conclusion of all of the experiments to ensure that consistent extinction-like behavior was reliably produced whenever saline was substituted for cocaine. Similar behavior during cocaine selfadministration would be expected following pretreatment with CP-154,526 if cocaine reinforcement was significantly reduced.

Once consistent and reproducible behavior during cocaine extinction was obtained, CP-154,526 testing during cocaine self-administration commenced. For the dose-response experiments, 18 rats were pretreated with CP-154,526 (10-40 mg/kg, i.p.) or vehicle $(5 \%$ emulphor in $0.9 \%$ saline) 30 min prior to the start of the behavioral session. Each rat was tested with each dose of CP-154,526 at least twice. CP-154,526 was tested on Tuesdays and Fridays provided that responding returned to baseline between test days. In order to determine the effects of CP-154,526 across several doses of cocaine, separate groups of rats were trained to selfadminister $0.125(n=14), 0.25(n=16)$ or $0.5(n=10)$ $\mathrm{mg} / \mathrm{kg}$ /infusion as described above. Once stable baselines of responding with cocaine and during extinction were obtained, the rats were pretreated with vehicle or CP-154,526 (20 mg/kg, i.p.) $30 \mathrm{~min}$ prior to the start of the behavioral session. Data collected included the total number of infusions and food pellets delivered per session as well as the number delivered during each of the four presentations of each component of the alternating schedule. For the cocaine extinction probes, data analyses only included those data obtained once the criteria for successful extinction-like behavior were met. Significance of the differences between the various treatments was determined with a one-way or two-way analysis of variance as appropriate. Tukey's all pairwise multiple comparison procedures were then used to isolate differences between groups.

\section{RESULTS}

Stable baselines of cocaine- and food-reinforced responding were obtained following approximately 15 to 20 experimental sessions with $0.25 \mathrm{mg} / \mathrm{kg} /$ infusion cocaine. The effects of CP-154,526 on the number of drug infusions at this dose are depicted in Figure 1. A oneway analysis of variance revealed a significant effect of CP-154,526 dose on self-administration $[F(5,99)=$ 23.176, $p<0.001$ ], with responding on the cocaine lever significantly reduced during cocaine extinction and following pretreatment with $20-40 \mathrm{mg} / \mathrm{kg}$ CP-154,526. Since there were no statistically significant differences between the effects of 20 or $40 \mathrm{mg} / \mathrm{kg}$ CP-154,526 on cocaine self-administration, the lower dose (i.e., $20 \mathrm{mg}$ / 


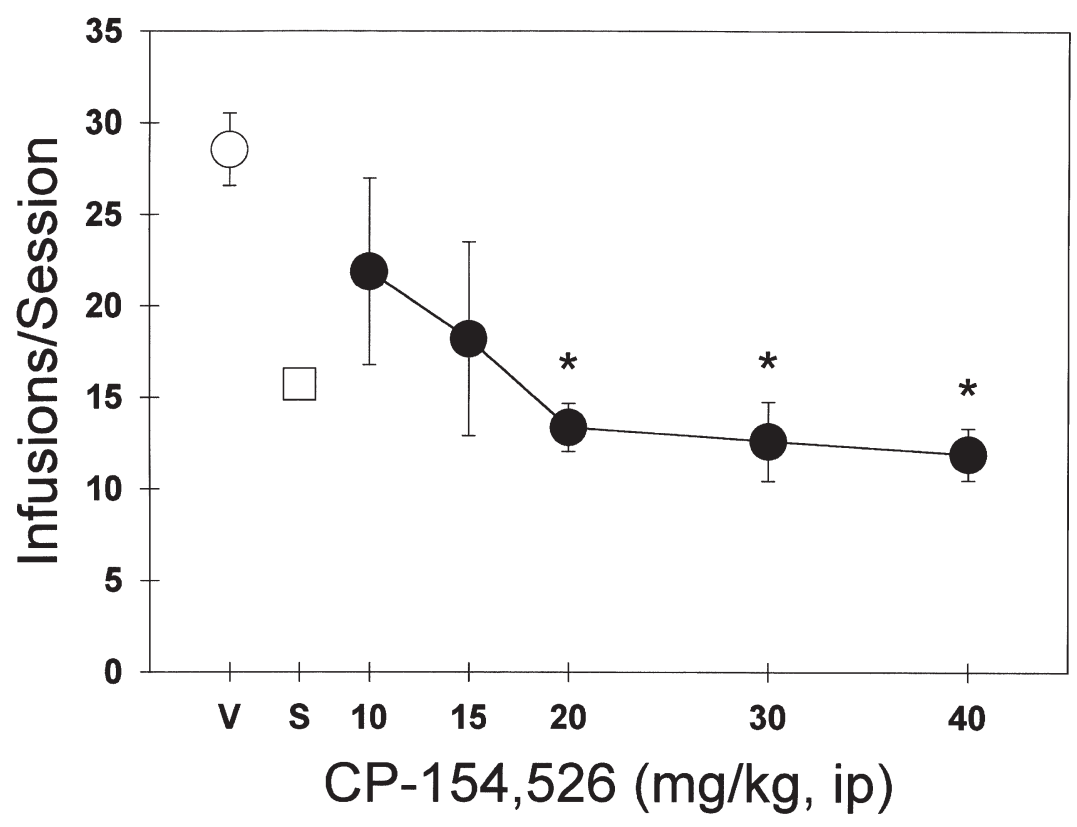

Figure 1. Effects of pretreatment (30 $\mathrm{min})$ with CP-154,626 (0-40 mg/kg, i.p.) on intravenous cocaine self-administration $(0.25$ $\mathrm{mg} / \mathrm{kg} /$ infusion $)$ in rats $(n=18)$. The open circle represents the effects of the vehicle $(5 \%$ emulphor in $0.9 \%$ saline), the open square represents responding during extinction (saline substitution) and the closed circles represent the various doses of CP-154,526. Responding was significantly decreased following $20-40 \mathrm{mg} / \mathrm{kg} \mathrm{CP}-154,526 .{ }^{*} p<$ $.05 \mathrm{CP}-154,526$ compared to vehicle pretreatment. $\mathrm{kg}$, i.p.) was used in all subsequent testing. The effects of CP-154,526 on the total number of infusions and food presentations delivered per session with the three different doses of cocaine (i.e., $0.125,0.25$ and $0.5 \mathrm{mg} / \mathrm{kg} /$ infusion) are shown in Figures 2 and 3, respectively. A two-way analysis of variance demonstrated a significant effect of cocaine dose $[\mathrm{F}(2,230)=32.399, p<.001]$ and treatment condition $[\mathrm{F}(3,230)=109.379, p<.001]$ on the total number of infusions self-administered. There was also a significant dose $\times$ treatment interaction $[\mathrm{F}(6,230)=10.356, p<.001]$. The number of infu- sions was significantly reduced during cocaine extinction and following pretreatment with CP-154,526 in rats trained to self-administer cocaine at each of the three doses tested (i.e., $0.125,0.25$ or $0.5 \mathrm{mg} / \mathrm{kg} /$ infusion). There was also a significant effect of cocaine dose $[\mathrm{F}(2,230)=7.746, p<.001]$ and treatment condition $[\mathrm{F}(3,230)=4.774, p=.003]$ on the number of food presentations per session, but no treatment $\times$ dose interaction $[F(6,230)=1.394]$. Although the number of food presentations delivered during cocaine extinction (i.e., saline substitution) was significantly greater than that

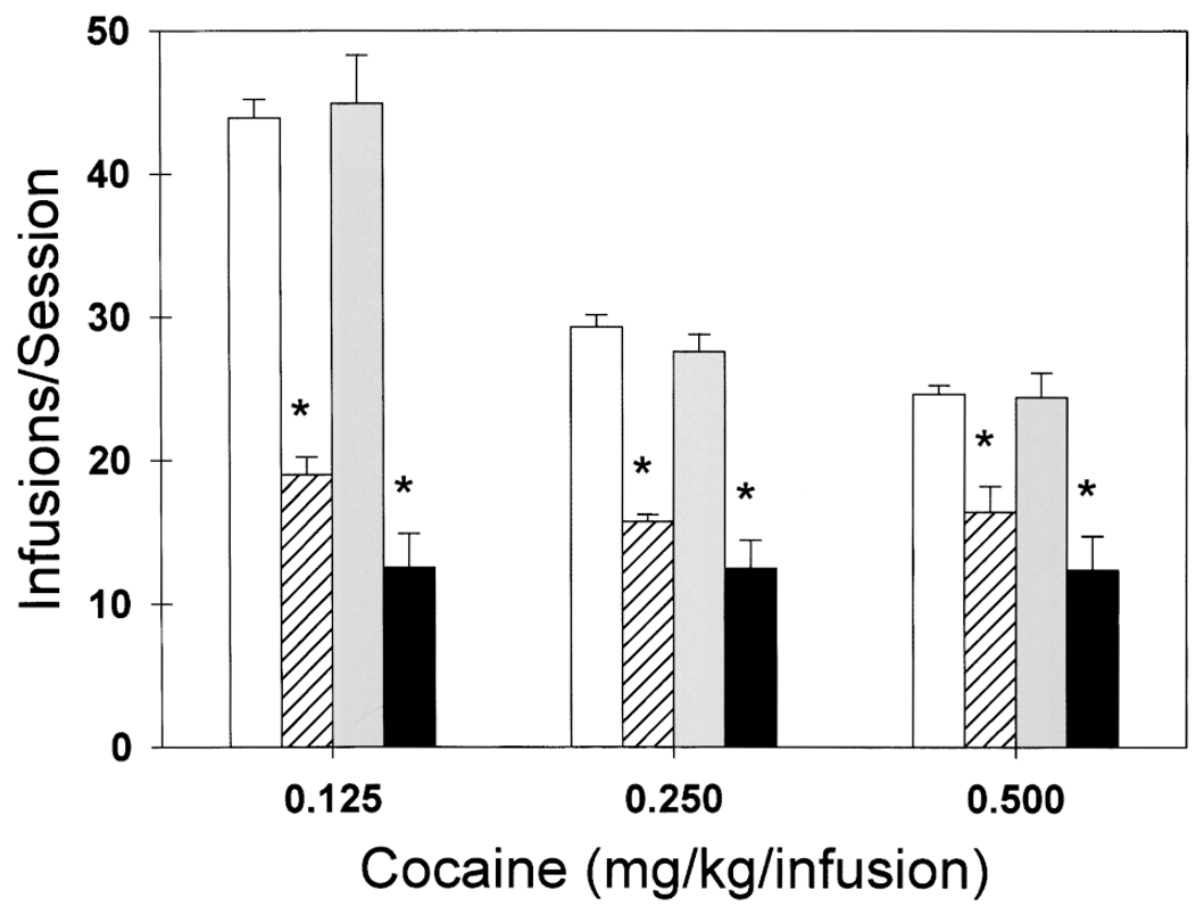

Figure 2. Effects of CP-154,526 (20 $\mathrm{mg} / \mathrm{kg}$, i.p.) on the number of infusions delivered by rats trained to self-administer three doses of cocaine $(0.125,0.25$ and $0.5 \mathrm{mg} / \mathrm{kg} /$ infusion). Open bars represent baseline cocaine selfadministration, striped bars represent saline infusions delivered during extinction, gray bars represent cocaine infusions delivered following pretreatment with vehicle, and closed bars represent infusions delivered following pretreatment with CP-154,526. The number of infusions was significantly reduced during extinction and following pretreatment with CP-154,526 at each of the cocaine doses tested. ${ }^{*} p<0.05$ extinction vs. baseline and CP-154,526 vs vehicle pretreatment. 


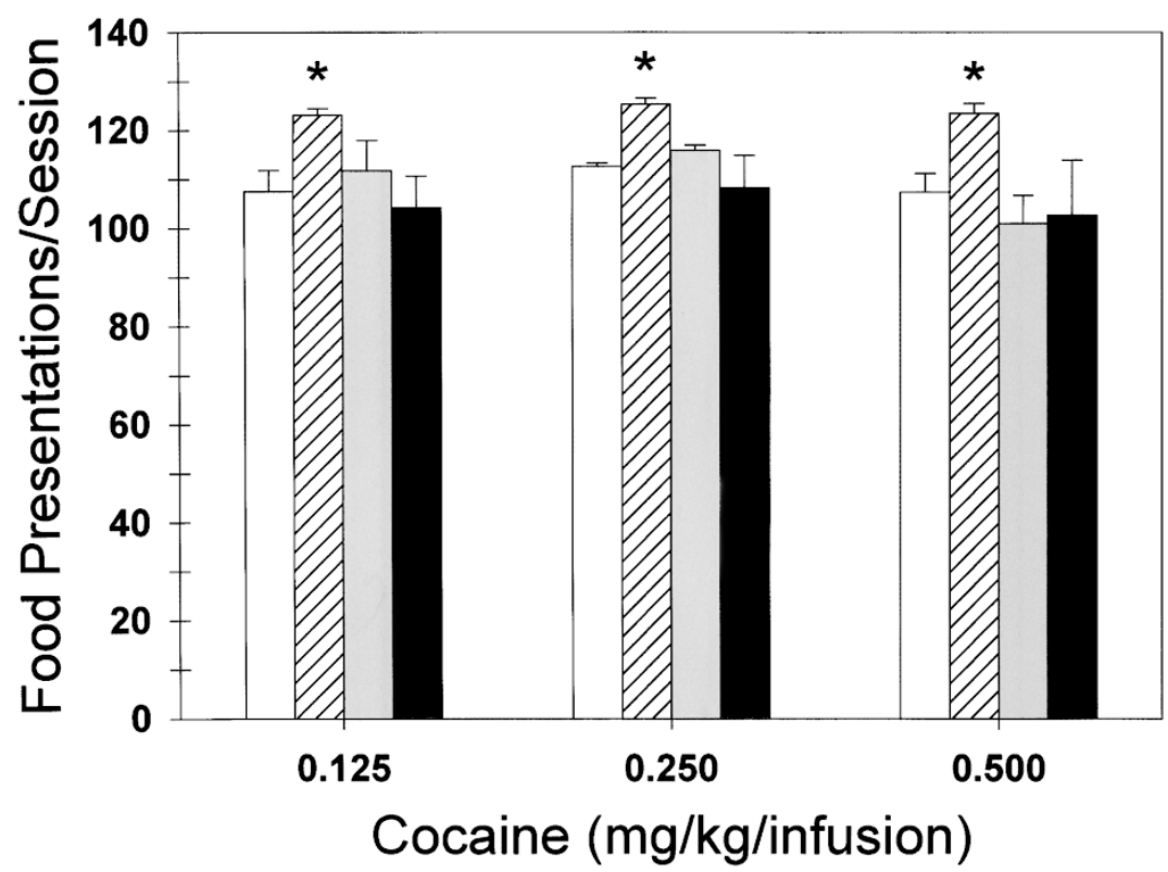

Figure 3. Effects of CP-154,526 (20 $\mathrm{mg} / \mathrm{kg}$, i.p.) on the number of food presentations obtained by rats trained to self-administer three doses of cocaine $(0.125,0.25$ and $0.5 \mathrm{mg} / \mathrm{kg} /$ infusion). Open bars represent baseline food deliveries, striped bars represent food presentations delivered during cocaine extinction, gray bars represent food presentations delivered following pretreatment with vehicle, and closed bars represent food pellets obtained following pretreatment with CP-154,526. The number of food presentations was significantly increased during extinction (saline substitution) compared to each of the other treatment conditions. ${ }^{*} p<.05$ extinction vs. baseline and CP-154,526 pretreatment. delivered during baseline $(q=4.825)$ or following pretreatment with CP-154,526 (q = 4.909), there were no other statistically significant effects, which simply indicates that the self-administered cocaine-induced intoxication produced a very modest, albeit significant, decrement in the ability of the rats to obtain as many food reinforcers as when not intoxicated (i.e., during saline substitution for cocaine).

The number of infusions delivered during each of the four 15-min self-administration bins per session for each of the three doses of cocaine is depicted in Figure 4. With $0.125 \mathrm{mg} / \mathrm{kg} /$ infusion as the self-administration dose (Figure 4, upper panel), a two-way analysis of variance revealed a significant effect of treatment condition $[\mathrm{F}(3,363)=2.680, p<.05]$ and 15 -min selfadministration bin $[\mathrm{F}(3,363)=154.313, p<.001]$ as well as a treatment $\times$ bin interaction $[\mathrm{F}(9,363)=3.848, p<$ .001]. The number of infusions delivered following pretreatment with CP-154,526 was significantly decreased compared to vehicle pretreatment during each of the four 15 -min self-administration bins, and there were no differences between the number of infusions delivered during cocaine extinction and following pretreatment with CP-154,526 during the second, third and fourth 15min bin. Similar results were obtained from rats trained to self-administer $0.25 \mathrm{mg} / \mathrm{kg}$ /infusion cocaine (Figure 4, middle panel). A two-way analysis of variance indicated a significant effect of treatment condition $[\mathrm{F}(3.335)=7.936, p<.001]$ and 15 -min self-administration bin $[\mathrm{F}(3,335)=90.607, p<.001]$ with a significant treatment $\times$ bin interaction $[\mathrm{F}(9,335)=4.286, p<.001]$ as well. While the number of infusions delivered during the first 15-min bin was less than all other treatment conditions following pretreatment with CP-154,526, the number of infusions obtained during cocaine extinction and following pretreatment with CP-154,526 was significantly reduced compared to vehicle pretreatment during the second, third and fourth self-administration bins. This same trend was even observed when the cocaine dose was increased to $0.5 \mathrm{mg} / \mathrm{kg} /$ infusion (Figure 4 , bottom panel). A two-way analysis of variance indicated a significant effect of treatment condition $[\mathrm{F}(3.223)=2.917, p<.05]$ and 15 -min self-administration bin $[\mathrm{F}(3,223)=40.751, p<.001]$ with a significant treatment $\times$ bin interaction $[\mathrm{F}(9,223)=4.124, p<.001]$ as well. Once again, the number of infusions obtained during cocaine extinction and following pretreatment with CP-154,526 was significantly reduced compared to vehicle pretreatment during the second, third and fourth self-administration bins. During the first $15 \mathrm{~min}$, however, the number of infusions delivered following pretreatment with CP-154,526 was also significantly less than that observed following each of the other treatment conditions.

\section{DISCUSSION}

The results of these experiments suggest that CRH receptors are involved in the maintenance of ongoing cocaine self-administration in rats. CP-154,526 binds with a high affinity $(\mathrm{Ki}<10 \mathrm{nM})$ to the CRH1 receptor subtype (Schulz et al. 1996), suggesting that the effects of the compound on cocaine self-administration resulted primarily from interactions at this receptor site. While there is the possibility that this compound may also affect other 


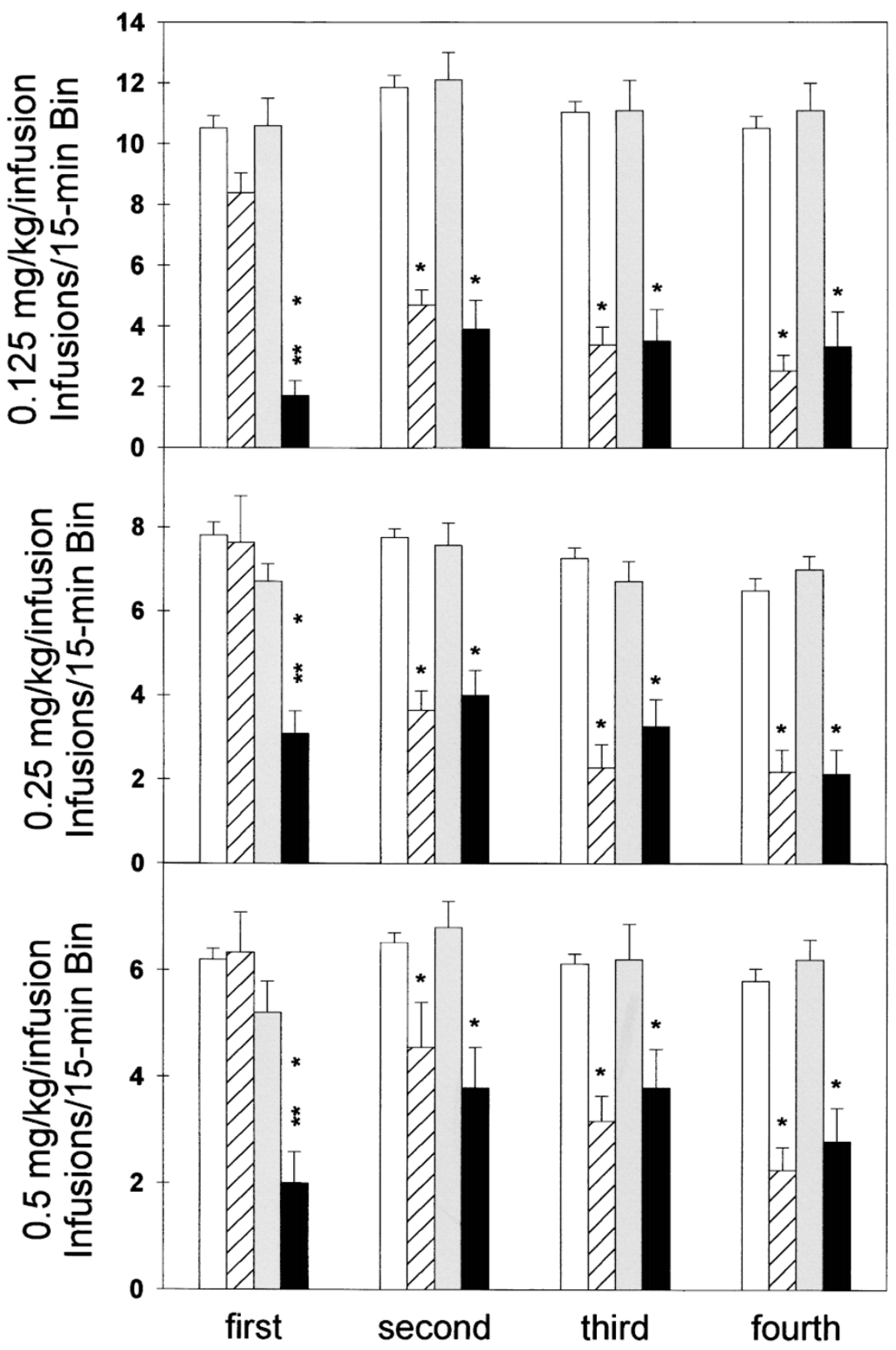

Figure 4. (Upper panel) Effects of CP-154,526 (20 mg/kg, i.p.) during each of the four 15-min self-administration bins on infusions self-administered by rats trained to self-administer $0.125 \mathrm{mg} / \mathrm{kg} /$ infusion cocaine. Open bars represent baseline cocaine self-administration, striped bars represent saline infusions delivered during cocaine extinction, gray bars represent cocaine infusions delivered following pretreatment with vehicle, and closed bars represent cocaine infusions delivered following pretreatment with CP-154,526. The number of infusions delivered during extinction was significantly less than baseline in the second, third and fourth 15-min self-administration bin. The number of cocaine infusions delivered following pretreatment with CP-154,526 was significantly reduced in all four of the 15-min self-administration bins, including the first 15-min bin. (Middle panel) Effects of CP-154,526 (20 mg/kg, i.p.) during each of the four 15-min self-administration bins on infusions self-administered by rats trained to self-administer $0.25 \mathrm{mg} / \mathrm{kg} /$ infusion cocaine. The number of infusions delivered during extinction was significantly less than baseline in the second, third and fourth 15-min self-administration bin. The number of cocaine infusions delivered following pretreatment with CP-154,526 was significantly reduced in all four of the 15-min self-administration bins, including the first 15-min bin. (Lower panel) Effects of CP-154,526 (20 mg/kg, i.p.) during each of the four 15-min self-administration bins on infusions self-administered by rats trained to self-administer $0.5 \mathrm{mg} /$ $\mathrm{kg}$ /infusion cocaine. The number of infusions delivered during extinction was significantly less than baseline in the second, 
binding sites, its selectivity and specificity for the CRH1 receptor make this possibility unlikely (Schulz et al. 1996; McCarthy et al. 1999). Cocaine-reinforced responding was decreased across several doses of cocaine, with the dose-response curve for cocaine self-administration shifted downward and flattened (Figure 2), suggesting that CP-154,526 was decreasing cocaine reinforcement. Interestingly, self-administration was decreased even at the highest dose tested (i.e., $0.5 \mathrm{mg} / \mathrm{kg} /$ infusion), which was noticeably different from the effects we observed with ketoconazole (Goeders et al. 1998). Ketoconazole was only effective in reducing drug intake at the lower unit doses of cocaine (i.e., $0.25 \mathrm{mg} / \mathrm{kg} /$ infusion or lower). No significant effects were observed when the higher dose (i.e., $0.5 \mathrm{mg} / \mathrm{kg} /$ infusion) was self-administered, suggesting that pretreatment with $\mathrm{CP}-154,526$ produced a more efficient inhibition of cocaine reinforcement. This decrease in cocaine self-administration was not likely due to nonspecific effects of the antagonist since food-maintained responding during the same session was unaffected by pretreatment with CP-154,526. However, food-maintained responding following $\mathrm{CP}-$ 154,526 pretreatment was similar to that observed following vehicle pretreatment even though the number of cocaine infusions was significantly reduced. During extinction, when saline was delivered instead of cocaine, there was a small but significant increase in the number of food presentations earned. It is not clear why the number of food presentations delivered following CP-154,526 pretreatment did not increase to levels observed during cocaine extinction, but this may have resulted from the amount of cocaine that was still self-administered. Even though it was less than following vehicle pretreatment, the amount of cocaine delivered may have still been sufficient to slightly reduce food-maintained responding.

We have employed food as a non-drug, alternate reinforcer for several years now using the same alternating schedule that we described for these experiments. As stated previously (Goeders et al. 1998), although food extinction probes were not specifically programmed in these experiments, the food pellet dispensers we use do malfunction from time to time. Therefore, these rats received multiple, random food extinction probes throughout the course of these experiments. Under these conditions, the rats rapidly learned to stop responding on the "food" lever whenever the food pellet dispensers malfunctioned (i.e., during a non-programmed food extinction probe), which suggests that the relative lack of effect of CP-154,526 on food-maintained responding was not the result of a lack of experience with food extinction. In addition, while food- maintained responding was maintained under a FR10 schedule of reinforcement, cocaine was self-administered under a FR4 schedule, suggesting that the different rates of responding on the two levers could have contributed to the differential effects of CP-154,526 on the two reinforcers. This is unlikely, however, since a greater effect would be expected against responding maintained at a higher rate (i.e., on the food lever). Nevertheless, preliminary data from our laboratory using equal schedules of reinforcement for both food and cocaine (i.e., FR4) have shown that CP-154,526 produces similar effects under both variations of the alternating reinforcer paradigm, suggesting that this may not have been an important factor in these experiments. However, additional research will be necessary to conclusively answer this question.

Another finding from these experiments was that responding on the cocaine lever following CP-154,526 pretreatment was significantly decreased even during the first 15-min bin. Typically, rats continue to respond during the first few minutes of the behavioral sessions even during extinction (Goeders et al. 1998), probably as a result of conditioning and related events associated with attaching the catheter and leash and the rat being placed into the self-administration environment at the start of the session (Peltier et al. 1999). Preliminary data from our laboratory suggest that such a conditioning effect, mediated at least in part via the HPA axis, occurs even in rats in which cocaine lever pressing has been successfully extinguished. We are currently investigating the role for CRH receptors and CP-154,526 in this conditioning phenomenon during cocaine extinction and using a conditioned cue reinstatement model (Goeders et al. 2000).

CRH has been implicated in many of the behavioral effects of cocaine, which is not surprising since the behavioral profiles of CRH and cocaine are very similar in many respects, such as the production of anxiety (Britton et al. 1984; Yang et al. 1992, Goeders 1997). Furthermore, in contrast to the effects of adrenocorticosteroids, the well-characterized interactions of CRH with membrane receptors make it a more attractive candidate as a mediator of the acute neurobehavioral effects of cocaine. For example, the central administration of $\alpha$-helical-CRF ${ }_{9-41}$ or of an anti-CRH antibody results in an attenuation of cocaine-induced locomotor activity (Sarnyai et al. 1992b), while icv CRH augments amphetamine-induced stereotyped behavior (Cole and Koob 1989) as well as cocaine-kindled seizures and lethality (Weiss et al. 1992). CRH may also provide a potential substrate for stressor-cocaine interactions. The central,

third and fourth 15-min self-administration bin. The number of cocaine infusions delivered following pretreatment with $\mathrm{CP}-$ 154,526 was significantly reduced in all four of the 15 -min self-administration bins, including the first 15 -min bin. ${ }^{*} p<.05$ extinction vs. baseline and CP-154,526 vs. vehicle pretreatment. ${ }^{* *} p<.05$ extinction vs. CP-154-526 pretreatment. 
but not peripheral, administration of $\alpha$-helical-CRF ${ }_{9-41}$ blocks the restraint stress-induced cross-sensitization of the behavioral response to amphetamine (Cole et al. 1990), while the central, but not systemic, administration of CRH itself induces behavioral sensitization in a manner analogous to amphetamine or stressors (Cador et al. 1993).

These findings have been extended to include a role for $\mathrm{CRH}$ in the effects of stressors on cocaine-seeking behavior. The icv administration of the CRH antagonist, D-Phe $\mathrm{CRF}_{12-41}$ (Erb et al. 1998), or the systemic administration of CP-154,526 (Shaham et al. 1998), attenuates the electric footshock-induced reinstatement of extinguished cocaine-seeking behavior in rats. CRH receptor blockade also reduces the electric footshockinduced reinstatement of extinguished heroin seeking (Shaham et al. 1997, 1998). On the other hand, the icv administration of CRH can reinstate extinguished heroin-seeking behavior (Shaham et al. 1997), although similar effects on extinguished cocaine seeking have not yet been reported. These data suggest that electric footshock reinstates extinguished cocaine- and heroin-seeking behavior, at least in part, through the stressinduced stimulation of CRH secretion from the hypothalamus, with the subsequent activation of the HPA axis. The ability of electric footshock to reinstate cocaine seeking probably also involves corticosterone, since adrenalectomy (Erb et al. 1998) or the inhibition of corticosterone synthesis (Mantsch and Goeders 1999) each attenuates stress-induced reinstatement. Furthermore, replenishing plasma corticosterone to minimal basal concentrations restores the ability of electric footshock to produce reinstatement in adrenalectomized rats (Erb et al. 1998). Electric footshock-induced reinstatement can still be blocked by D-Phe CRF $\mathrm{Cl}_{12-41}$ in these rats, indicating that corticosterone may be playing a "permissive" role in the CRH-mediated reinstating effects of electric footshock, such that corticosterone may actually be required for the actions of the neuropeptide.

Cocaine has also been reported to induce a number of changes in the expression of CRH and its receptors within the central nervous system. Acute cocaine administration reduces CRH-like immunoreactivity in the hypothalamus (Sarnyai et al. 1993), an effect believed to reflect the release of the peptide into the portal circulation from the median eminence where it exerts its effects on neuroendocrine function. Cocaine also affects $\mathrm{CRH}-$ like immunoreactivity in a number of other brain regions that are not thought to be directly linked to pituitary-adrenal activity, including the hippocampus, frontal cortex, basal forebrain, and amygdala (Sarnyai et al. 1993; Gardi et al. 1997). Interestingly, in contrast to the reduction in CRH-like immunoreactivity seen in the hypothalamus, frontal cortex, hippocampus, and basal forebrain, cocaine has been reported to dramatically and dose-dependently increase the expression of $\mathrm{CRH}$ in the amygdala (Sarnyai et al. 1993; Gardi et al. 1997). This effect appears to reflect cocaine-induced increases in CRH synthesis and release because increases in extracellular CRH have also been characterized in the amygdala following an acute injection of cocaine (Richter et al. 1995) and during withdrawal from cocaine self-administration (Richter and Weiss 1999), and because increases in CRH mRNA are observed with acute "binge-pattern" cocaine administration (Zhou et al. 1996). Further evidence for this premise is provided by our findings that $\mathrm{CRH}$ receptors are down-regulated in the amygdala following chronic cocaine delivery (Goeders et al. 1990). These data suggest that the cocaine-induced increase in the synthesis and/or release of CRH in this region may mediate some of the behavioral effects of the drug. In fact, a role for the amygdala in psychomotor stimulant self-administration (Deminiére et al. 1988; Caine et al. 1995; Hurd et al. 1997) and relapse to drug seeking (Baker et al. 1999) has already been established. Interestingly, this role appears to at least partially involve the classical conditioning of drug effects (Whitelaw et al. 1996; Meil and See 1997), a process that is obviously intimately involved in the persistence and relapse of cocaine-seeking behavior and may also be related to the ability of $\mathrm{CP}-154,526$ to reduce cocaine self-administration even during the first few minutes of the behavioral session. Central CRH has been implicated in the conditioned effects of cocaine (De Vries et al. 1998; De Vries and Pert 1998), although it is unclear whether or not these effects are the result of $\mathrm{CRH}$ 's actions within the amygdala.

Cocaine affects $\mathrm{CRH}$ activity within the mesocorticolimbic dopaminergic neuronal system, a system widely regarded to mediate the reinforcing effects of cocaine and other drugs of abuse (Koob and Bloom 1988). Acute cocaine delivery decreases CRH-like immunoreactivity (Sarnyai et al. 1993; Gardi et al. 1997) and increases CRH mRNA (Zhou et al. 1996) in the medial prefrontal cortex. Chronic cocaine administration reduces CRH receptor binding in the medial prefrontal cortex and nucleus accumbens (Goeders et al. 1990; Ambrosio et al. 1997), effects which may be secondary to drug-induced increases in the release of the neuropeptide. In contrast to the effects seen in these terminal regions, CRH receptor binding is actually increased in the ventral tegmental area (VTA). The localization of $\mathrm{CRH}$ and its receptors within this system suggests that the peptide may have modulatory effects on dopaminergic neurotransmission. Accordingly, the administration of CRH directly into the VTA results in a timedependent decrease in prefrontal cortical dopamine metabolism with an increase in dopamine turnover in the nucleus accumbens (Kalivas et al. 1987). This general pattern of dopaminergic neurotransmission has previously been associated with an enhanced vulnerability to engage in psychomotor stimulant self-adminis- 
tration (Piazza et al. 1991; Goeders and Smith 1993). However, the effects of intra-VTA CRH are very different from those reported following the icv administration of the peptide. ICV CRH has little or no effect on dopamine in the nucleus accumbens (Kalivas et al. 1987; Dunn and Berridge 1990) and actually increases dopamine metabolism in the medial prefrontal cortex (Dunn and Berridge 1990). Nevertheless, in consideration of the putative dual role for the medial prefrontal cortex in the neurobiological response to stress as well as in the initiation of cocaine-seeking behavior (Goeders and Smith 1983; Goeders 1997), it is likely that CRHinduced alterations in dopaminergic neurotransmission play an important role in this peptide's effects on cocaine responsiveness.

\section{ACKNOWLEDGMENTS}

We thank Dr. Robert Mansbach of Pfizer Central Research, Groton, CT, for the generous gift of CP-154,526. This research was supported by USPHS grant DA06013 from the National Institute on Drug Abuse.

\section{REFERENCES}

Ambrosio E, Sharpe LG, Pilotte NS (1997): Regional binding to corticotropin releasing factor receptors in brain of rats exposed to chronic cocaine and cocaine withdrawal. Synapse 26:272-276

Baker DA, Fuchs RA, Tran-Nguyen LT, Palmer AJ, Marshall JF, McPherson RJ, Neisewander JL (1999): Cocaine-seeking behavior and Fos expression in the amygdala produced by cocaine or a cocaine self-administration environment. Ann NY Acad Sci 877:796-799

Baumann MH, Gendron TM, Becketts KM, Henningfield JE, Gorelick DA, Rothman RB (1995): Effects of intravenous cocaine on plasma cortisol and prolactin in human cocaine abusers. Biol Psychiatry 38:751-755

Britton DR, Hoffman DK, Lederis K, Rivier J (1984): A comparison of the behavioral effects of CRF, sauvagine and urotensin I. Brain Res 304:201-205

Borowsky B, Kuhn CM (1991): Monoamine mediation of cocaine-induced hypothalamo-pituitary-adrenal activation. J Pharmacol Exp Ther 256:204-210

Cador M, Cole BJ, Koob GF, Stinus L, Le Moal M (1993): Central administration of corticotropin-releasing factor induces long-term sensitization to D-amphetamine. Brain Res 606:181-186

Caine SB, Heinrichs SC, Coffin VL, Koob GF (1995): Effects of the dopamine D-1 antagonist SCH 23390 microinjected into the accumbens, amygdala or striatum on cocaine self-administration in the rat. Brain Res 692:47-56

Cole BJ, Koob GF (1989): Low doses of corticotropin-releasing factor potentiate amphetamine-induced stereotyped behavior. Psychopharmacology 99:27-33

Cole BJ, Cador M, Stinus L, Rivier J, Vale W, Koob GF, Le Moal M (1990): Central administration of a CRF antago- nist blocks the development of stress-induced behavioral sensitization. Brain Res 512:343-346

Deminiére JM, Taghzouti K, Tassin JP, Le Moal M, Simon H (1988): Increased sensitivity to amphetamine and facilitation of amphetamine self-administration after 6-hydroxydopamine lesions of the amygdala. Psychopharmacology 94:232-236

De Vries AC, Pert A (1998): Conditioned increases in anxiogenic-like behavior following exposure to contextual stimuli associated with cocaine are mediated by corticotropinreleasing factor. Psychopharmacology 137:333-340

De Vries AC, Taymans SE, Sundstrom JM, Pert A (1998): Conditioned release of corticosterone by contextual stimuli associated with cocaine is mediated by corticotropin-releasing factor. Brain Res 786:39-46

Dunn AJ, Berridge CW (1990): Physiological and behavioral responses to corticotropin-releasing factor administration: is CRF a mediator of anxiety or stress responses? Brain Res Rev 15:71-100

Erb S, Shaham Y, Stewart J (1998): The role of corticotropinreleasing factor and corticosterone in stress- and cocaine-induced relapse to cocaine seeking in rats. J Neurosci 18:5529-5536

Gardi J, Biro E, Sarnyai Z, Vecsernyes M, Julesz J, Telegdy G (1997): Time-dependent alterations in corticotropinreleasing factor-like immunoreactivity in different brain regions after acute cocaine administration to rats. Neuropeptides 31:15-18

Goeders NE, Smith JE (1983): Cortical dopaminergic involvement in cocaine reinforcement. Science 221:773-775

Goeders NE, Bienvenu OJ, De Souza EB (1990): Chronic cocaine administration alters corticotropin-releasing factor receptors in the rat brain. Brain Res 531:322-328

Goeders NE, Smith JE (1993): Intracranial cocaine self-administration into the medial prefrontal cortex increases dopamine turnover in the nucleus accumbens. J Pharmacol Exp Ther 265:592-600

Goeders NE, Guerin GF (1996): Role for corticosterone in intravenous cocaine self-administration in rats. Neuroendocrinology 64:337-348

Goeders NE (1997): A neuroendocrine role in cocaine reinforcement. Psychoneuroendocrinology 22:237-259

Goeders NE, Peltier RL, Guerin GF (1998): Ketoconazole reduces low dose cocaine self-administration in rats. Drug Alcohol Dependence 53:67-77

Goeders NE, Clampitt D, Peltier RL, Guerin GF (2000): Reinstatement of cocaine-seeking behavior using a conditioned reinforcer: Role for the hypothalamo-pituitaryadrenal (HPA) axis. In Harris LS (ed), NIDA Research Monograph, Problems of Drug Dependence, 1999, NIH Publication 00-4737. Bethesda, MD, NIH, p 92

Hurd YL, McGregor A, Ponten M (1997): In vivo amygdala dopamine levels modulate cocaine self-administration behaviour in the rat: D1 dopamine receptor involvement. Eur J Neurosci 9:2541-2548

Kalivas PW, Duffy P, Latimer G (1987): Neurochemical and behavioral effects of corticotropin-releasing factor in the ventral tegmental area of the rat. J Pharmacol Exp Ther 242:757-763

Koob GF, Goeders NE (1989): Neuroanatomical substrates of 
drug self-administration. In Liebman JM, Cooper SJ (eds), Oxford Reviews in Psychopharmacology, Vol. 1, Neuropharmacological Basis of Reward. London, Oxford University Press, pp 214-263

Koob GF, Bloom FE (1988): Cellular and molecular mechanisms of drug dependence. Science 242:715-723

Mansbach RS, Brooks EN, Chen YL (1997): Antidepressantlike effects of CP-154,526, a selective CRF1 receptor antagonist. Eur J Pharmacol 323:21-26

Mantsch JR, Goeders NE (1999): Ketoconazole blocks the stressor-induced reinstatement of cocaine-seeking behavior in rats: relationship to the discriminative stimulus effects of cocaine. Psychopharmacology 142:399-407

McCarthy JR, Heinrichs SC, Grigoriadis DE (1999): Recent advances with the CRF1 receptor: design of small molecule inhibitors, receptor subtypes and clinical implications. Cur Pharmacol Design 5:289-315

Meil WM, See RE (1997): Lesions of the basolateral amygdala abolish the ability of drug associated cues to reinstate responding during withdrawal from selfadministered cocaine. Behav Brain Res 87:139-148

Mendelson JH, Mello NK, Teoh SK, Ellingboe J, Cochin J (1989): Cocaine effects on the pulsatile secretion of anterior pituitary, gonadal, and adrenal hormones. J Clin Endocrinol Metab 69:1256-1260

Moldow RL, Fischman AJ (1987): Cocaine induced secretion of ACTH, beta-endorphin, and corticosterone. Peptides 8:819-822

Peltier RL, Guerin GF, Dorairaj NR, Irby BD, Goeders NE (1999): The effect of saline substitution tests on plasma corticosterone in rats trained to self-administer cocaine. In Harris LS (ed), NIDA Research Monograph, Problems of Drug Dependence, 1998. NIH publication 99-4395. Bethesda, MD, NIH, p 254

Piazza PV, Rougé-Pont F, Deminiére JM, Kharoubi M, Le Moal M, Simon H (1991): Dopaminergic activity is reduced in the prefrontal cortex and increased in the nucleus accumbens of rats predisposed to develop amphetamine self-administration. Brain Res 567:169-174

Richter RM, Merlo Pich E, Koob GF, Weiss F (1995): Sensitization of cocaine-stimulated increase in extracellular levels of corticotropin-releasing factor from the rat amygdala after repeated administration as determined by intracranial microdialysis. Neurosci Lett 187:169-172

Richter RM, Weiss F (1999): In vivo CRF release in rat amygdala is increased during cocaine withdrawal in self-administering rats. Synapse 32:254-261

Rivier CL, Vale W (1987): Cocaine stimulates adrenocorticotropin $(\mathrm{ACTH})$ secretion through a corticotropin-releasing factor (CRF)-mediated mechanism. Brain Res 422:403-406

Rivier C, Lee S (1994): Stimulatory effects of cocaine on ACTH secretion: role of the hypothalamus. Mol Cell Neurosci 5:189-195
Sarnyai Z, Biro E, Penke B, Telegdy G (1992a): The cocaineinduced elevation of plasma corticosterone is mediated by endogenous corticotropin-releasing factor (CRF) in rats. Brain Res 589:154-156

Sarnyai Z, Hohn J, Szabo G, Penke B (1992b): Critical role of endogenous corticotropin-releasing factor (CRF) in the mediation of the behavioral action of cocaine in rats. Life Sci 51:2019-2024

Sarnyai Z, Biro E, Gardi J, Vecsernyes M, Julesz J, Telegdy G (1993): Alterations of corticotropin-releasing factor-like immunoreactivity in different brain regions after acute cocaine administration in rats. Brain Res 616:315-319

Sarnyai Z, Mello NK, Mendelson JH, Eros-Sarnyai M, Mercer G (1996): Effects of cocaine on pulsatile activity of the hypothalamic-pituitary-adrenal axis in male rhesus monkeys: neuroendocrine and behavioral correlates. J Pharmacol Exp Ther 277:225-234

Schulz DW, Mansbach RS, Sprouse J, Braselton JP, Collins J, Corman M, Dunaiskis A, Faraci S, Schmidt AW, Seeger T, Seymour P, Tingley FD, Winston EN, Chen YL, Heym J (1996): CP-154,526: a potent and selective nonpeptide antagonist of corticotropin releasing factor receptors. Proc Natl Acad Sci USA 93:10477-10482

Shaham Y, Funk D, Brown TJ, Walker C-D, Stewart J (1997): Corticotropin-releasing factor, but not corticosterone, is involved in stress-induced relapse to heroin-seeking in rats. J Neurosci 17:2605-2614

Shaham Y, Erb S, Leung S, Buczek Y, Stewart J (1998): CP154,526 , a selective non-peptide antagonist of the corticotropin-releasing factor $_{1}$ receptor attenuates stressinduced relapse to drug-seeking behavior in cocaine- and heroin-trained rats. Psychopharmacology 137:184-190

Teoh SK, Sarnyai Z, Mendelson JH, Mello NK, Springer SA, Sholar JW, Wapler M, Kuehnle JC, Gelles H (1994): Cocaine effects on pulsatile secretion of ACTH in men. J Pharmacol Exp Ther 270:1134-1138

Weiss SR, Nierenberg J, Lewis R, Post RM (1992): Corticotropin-releasing hormone: potentiation of cocaine-kindled seizures and lethality. Epilepsia 33:248-254

Whitelaw RB, Markou A, Robbins TW, Everitt BJ (1996): Excitotoxic lesions of the basolateral amygdala impair the acquisition of cocaine-seeking behaviour under a second-order schedule of reinforcement. Psychopharmacology 127:213-224

Yang XM, Gorman AL, Dunn AJ, Goeders NE (1992): Anxiogenic effects of acute and chronic cocaine administration: neurochemical and behavioral studies. Pharmacol Biochem Behav 41:643-650

Zhou Y, Spangler R, LaForge KS, Maggos CE, Ho A, Kreek MJ (1996): Corticotropin-releasing factor receptor messenger RNAs in rat brain and pituitary during "binge"pattern cocaine administration and withdrawal. J Pharmacol Exp Ther 279:351-358 